\title{
Religion, Psychology and Globalisation Process: Attitudinal Appraisal
}

\author{
Emmanuel Orok Duke \\ Lecturer, Department of Religious and Cultural Studies \\ University of Calabar, Calabar, Nigeria
}

\begin{abstract}
A key consequence of globalisation is the integrative approach to reality whereby emphasis is placed on interdependence. Religion being an expression of human culture is equally affected by this cultural revolution. The main objective of this paper is to examine how religious affiliation, among Christians, influences attitudes towards the application of psychological sciences to the assuagement of human suffering. The sociological theory of structural functionalism was deployed to explain attitudinal appraisal. Ethnographic methodology, through quantitative analysis of administered questionnaire, was also used. The study reveals that religious tenets largely shape attitudinal appraisal and redefine the borders of globalisation's metanarratives.
\end{abstract}

Keywords: globalisation process, psychological sciences, religious affiliation, pastoral care, attitudinal appraisal

The symbiotic relationship between culture and religion is widely studied in sociology of religion from various perspectives. Changing patterns in Christianity and its religious cultures within Nigerian society, as regards psychology and pastoral counselling, are at the centre of this study. Scholars of religion are interested in these developments as they seek to give phenomenological and theoretical interpretations to the way in which a religion responds to changing cultural patterns in a given society (Duke, 2014, p. 49).

There are multidimensional approaches to the study of religion. This is because human understanding of things that pertain to ultimate realities permeates almost all the facets of life. 
Thus, Jonte-Pace and Parsons (2001) maintain that dialogue between psychology and religion has revolutionised the field of psychology of religion thereby improving the totality of the wellbeing of human persons (p.3). In a related study, Kinnvall (2004) examines how globalisation has shaped religion and the politics of global security after 9/11 terrorists attack (pp. 741-742). In addition, Agara and Osawe (2012) indicate that modernism and globalisation render every totalising ideology as expressed in terrorism baseless because interconnectedness remains one of the benefits of civilisation (p. 183). For her part, Nanda examines the impact of globalisation on the Hindu population in India and observes that this phenomenon is not just improving religiosity but also deepening ethnic nationalism (2011, p.2). Ogbonnaya (2013) also reports that the transformation of the world through Internet technologies has heightened religious extremism and international insecurity in some radicalised communities around the world ( $\mathrm{p}$. 62). However, there is no written evidence that the changing patterns in religion, psychology and globalisation among Christians in Nigeria have been investigated. Hence, this study intends to fill this knowledge gap by appraising the attitudinal changes among members of selected Christian churches with regard to how developments in psychology and globalisation shape their existence in the society and their perspectives on religion.

The contemporary process of globalisation is a dominant social factor that is shaping cultural patterns within the society. It has encouraged intensive interrelationships among cultures and a deeper interest in how religious patterns are changing. The process of globalisation has, more than ever, overtly influenced the interdependence that drives the integrative approach to scientific investigations because it highlights interconnectivity and relatedness. This work investigates the relationship between psychological sciences and the practice of Christianity as well as how globalisation processes affect this integration among young Nigerians. Therefore, its concluding remarks will articulate these appraisals. Attitudinal appraisal is an important aspect of social psychology that aids the understanding of behavioural patterns. Greenwald (1989) describes attitudes as predispositions of human beings to respond to certain stimuli with particular responses. 
They designate cognitive, affective and behavioural responses to certain stimuli. Attitudes reinforce themselves and with time, become enduring systems of positive or negative evaluations, emotional feelings and assessment of tendencies towards social objects (p. 6). These explanations indicate that diverse stimuli are responsible for building one's attitude towards something or someone. Furthermore, after a period of time, one's attitude towards an important object or subject in a person's life often controls significantly his or her behaviour towards other realities. This study is divided into seven sections: (1) Introduction, (2) Understanding Contemporary Globalisation, (3) Social Theory of Structural Functionalism, (4) Religion and Psychological Sciences: Patterns of Emerging Partnership, (5) Methodology (6) Research Data: Analysis and Discussion and (7) Conclusion.

\section{Understanding Contemporary Globalisation}

Globalisation remains the distillation of cultural experiences shaped by human civilisations for more intensive interrelationships. Definitely, these experiences have historical antecedents. Ugwuanyi and Agwu (2012) support this claim in their work by highlighting three eras of globalisation: archaic, proto, and modern (pp. 80-81). According to them, archaic globalisation predates the 16th century (C.E) civilisation and it articulates commercial links between economic powers that shaped empires. Proto-globalisation embraces international relationships in the 16th and 17th centuries; this phase is characterised by maritime explorations and the 'discovery' of other parts of the world, colonisation of 'new' worlds and global economic integration processes. Modern globalisation was anticipated by scientific discoveries of preceding centuries and inaugurated in the 19th century with the birth of industrialisation and neo-imperialism. It was truncated by the two world wars of the twentieth century that hampered for a while economic exploitations of other nations and the expansionist agenda of the more powerful nations. As a result of this belligerent hiatus, the framework of international commerce and co-operation was developed with the help of international institutions led by the United States and European nations so that the desires of domineering nations would not annihilate the weaker ones 
anymore.

Various theories view contemporary globalisation as a product of modern technology and the mass sharing of cultural civilisations, driving the new international systems and world order towards the progress of the world. Though the term 'globalisation' is new, the thinking, theorising and praxis of global interconnectedness have been part and parcel of human history. Thomas Eriksen argues that the German Philosopher G. W. F. Hegel (1770-1831) is the first theorist of globalisation who, with his philosophy of connectedness as emerging consciousness, saw the future of human progress as a movement towards a global community under the guidance of Weltgeist: the world-spirit. In the light of this Hegelian Weltgeist, Eriksen (2007) views the contemporary perspectives on globalisation that delineate the possibilities within a new global community (p. 1). But if Hegelian Weltgeist is solely interpreted as Western culture and/or civilisations, Eriksen's proposition can hardly be accepted wholly because globalisation is not westernisation of other cultures and civilisations. It involves much more than that. Contemporary globalisation process involves give-and-take on the 'highways' of modern technological/communication systems. It is gradually becoming another metanarrative of this age.

Metanarratives are totalising or all-encompassing discourses that explain every other small story concerning human existence. The instrumentality of language metanarratives attempts to organise knowledge in such a way that it sustains social interactions and cohesion in the society. Russell (2011) argues that Lyotard identified two metanarratives in the modern European history, namely: the emancipatory narrative of progress and the speculative narrative of unity of all knowledge. He goes on to show why for Lyotard metanarratives are a definitive feature of modernity characterised by order, reason, stability and progress in favour of humankind (2011, pp. 699-700). As the fruit of modernisation, globalisation makes the latter to overlap with the former. And in line with modernity, globalisation thrives through the practicality of its metanarratives. Lewellen (2002) stresses this idea as follows: 
The metanarrative of globalization would go something like this: Globalization is impacting people everywhere by erasing local boundaries and transforming identities. Restrictive categories like tribal, peasant, community, local, and even culture are giving way to terms that emphasize blending, plasticity, and on-going identityconstruction: ethnic, hybrid, creole, national, and transnational. (p. 234)

The transformation of identity as stated in the above citation is a very complex process of assimilation and conflict. This is because the interface of cultures is sometimes threatened by some sort of resistance on the part of recipients/victims for various reasons. Yet, the osmotic penetration of one culture by the other through the membrane of media technology cannot be resisted for too long. Therefore, globalisation process is a complex and transnational reality of exchange that can be lopsided at times because of the power play involved.

The dialectics of globalisation shows that although this process transforms cultures, certain groups of people suffer isolation, exclusion or exploitation because of its operations. This occurs in every society as long as there is disparity between the rich and the poor, professionals and laymen, the powerful and the weak, the schooled and the unschooled. For this very reason, some are excluded from the benefits of the globalising process. This is evident, for example, in the demographics that show those who can use or have access to the Internet and those who cannot.

Since the present human condition is shaped by its pasts, globalisation is the product of past human endeavours and historical situations that are sustaining a process of cultural revolution and are redefining the vision and identity of contemporary world based on the logic of co-operation, progress and integration towards the wellbeing of humankind. This emerging system of social interactions affects the organisation of the society in so many ways. Thus it cannot be gainsaid that globalisation influences all facets of human life: cultural, political, religious, economical, educational, etc. From this flows the ongoing worldwide symbiosis of cultural civilisations.

The writer agrees with the opinion of Mozaffari (2002) 
which holds that for every civilisation there is an explicit world view driven by cultural systems and a coherent historical framework (p. 26). From this viewpoint, it can be seen that the contemporary understanding of globalisation is strongly driven by the spirit of connectivity, mediated through powerful technologies of information and the immensity of multiculturalism that are changing human interactions and relationships in the society. These technologies have expanded the media of globalisation through the Internet system, mass culture, writing, printing and mechanisation. For these reasons, Mott IV (2004) asserts that globalisation is not limited to commerce and economics, but extends to culture, politics, religion, ecology, language, information and every sphere of human life (p. 179).

Nonetheless, globalisation affects cultures, peoples and nations of the world differently. It has created opportunities of gain and dominance of some at the expense of many others who are exploited by it. For example, the United States of America has benefitted from the financial systems of globalisation more than any other nation while Chinese volume of trade is growing higher with 'made in China goods' flooding the global market. Sheri et al (2011) explain further:

Although globalization has transformed the cultures and life practices in all countries, the flow of resources, wealth and sociocultural practices between countries is asymmetrical. For instance, the United States has been a major exporter of pop culture, and China has been a main beneficiary of global trade. A productive way to begin the scientific study of the relationship between globalization and psychology is to examine the similarities and differences in the lay perceptions and appraisals of globalization and social change across nations (p. 664).

The network of social changes that arises from globalisation has compressed the world and intensified the consciousness of interconnectedness. Despite all this, Eriksen (2007) states that the force of homogeneity implicit in the globalisation process has not extinguished heterogeneity of its recipients, be it in the spheres of religion, business practices or sub-cultural practices. Consequently, globalisation creates tension between and within 
cultural groups (p. 4). This notwithstanding, it remains a beneficial process for our time.

In summary, Eriksen (2007) describes contemporary globalisation as a process that entails both the intensification and awareness of transnational connectedness. It is largely driven by technological and economic processes in a multidimensional way so much that every facet of human life is affected. The multidimensional character of globalisation is expressed in its homogenic and heterogenic effects that reverberate across all spheres of human life and geographical boundaries. From the foregoing, it can be deduced that this concept is wider than westernisation, neo-imperialism, transnational capitalism and commercialism. Finally, as experienced in the past 30 years, contemporary globalisation is marked by distinctive traits enhanced through mass communication technology and the global spread of capitalism (p. 14).

The above is just a terse and descriptive expositions of the concept designated as globalisation. From the foregoing, it can be said that globalisation is so pervasive that it is gradually becoming a cultural metaphor and stimulus that will shape studies on structural framework in contemporary sociology. According to Kövecses (2002), a metaphor, from a cognitive linguistic perspective, is a verbal instrument for 'understanding one conceptual domain in terms of another domain' (p. 4). Based on this perception, contemporary globalisation process is an emerging cultural metaphor practically drawn from the conceptual domain of historic transnational commerce and its dynamics that are bringing people from all corners of the world together for diverse forms of interactions through the help of mass technology. Hence, Harvey (2000) suggests that the assumption that globalisation is fast becoming a cultural metaphor for contemporary society is premised upon its influence on all spheres of life and emerging societal interactions that shape the society (p. 19). Given that globalisation is an emerging social force, the next section will examine how it is influencing structural frameworks that determine the functions of the society.

\section{Social Theory of Structural Functionalism}

This paper adopts social theory of structural functionalism 
to analyse how the emerging process of globalisation is changing contemporary religious structures and how young people are responding to it across faith denominational circles. Data from the administered questionnaire for this work show receptive and cautious approaches to the application of psychological sciences to the practice of Christianity. Some of the respondents acknowledged that the application of psychology to pastoral care is gradually changing the morphology of contemporary Christian praxis.

Functionalism or structural functionalism is a form of social theory that visualises the society as a complex system wherein the coherent ordering of its social structures and components guarantee its stability. Social theory is descriptively simplified as basic surviving skills within an organised system. This is premised on the assumption that if one knows the operations of an organised system, like the society, and fits into it, the one will live in relative peace and harmony (Lemert, 1999, pp. 1-2). Social theories are constructed modes of looking eat the society based on certain assumptions, self-identity and the end of its interactions. Thus these theories present social realities in perspectives and societal variables which necessarily engender modifications. That is why there is, for example, neo-structural functionalism.

There is a general consensus among scholars of sociology that Auguste Comte (1798-1857), a French philosopher and sociologist, laid the groundwork for the importance of social integration, especially when the society is undergoing rapid change. This integration is necessary because when social realities change, the adjustment to its social structures will facilitate the process of integration of all into the main fabric of the society, thereby reducing dysfunctional backlash. Herbert Spencer (18201901) and Emile Durkheim (1857-1917) built upon Comte's ideas. The success of their work led to the emergence of sociology as a distinct field in the sphere of social science. But it was Talcott Parsons (1902-1979) who popularised the structural-functional paradigm of social theory while Robert Merton (1910-2003) emphasised the role of agency that was lacking in the former's views (Macionis, 2005, pp. 14-15).

Henslin (2005) explains that Robert Merton's logic of 
structural functionalism does not only visualise the society as an organism butalso aids the understanding of changes that take place in human communities. Hence, the adjustments in social structures should be viewed as serving two functions: manifest and latent. The manifest functions are the ones that the society can predict and control whereas the latent ones are not directly intended. Hence, for every intended or pre-emptory adjustment to social structures, there are always positive or negative unintended effects (p. 13). For example, as the Chinese government relaxes its onechild-one family policy with a view to taking care of its aging population, future economic growth and other related issues, other social institutions will be affected by this programme and unintended results will follow.

For Martin (2009), social structures are analytic constructs that build relationships among active agents in the society. It is these relationships that constitute social institutions (p. 17). The family, marriage, religion, health, economy, politics, etc., are but few examples of social structures and institutions that perform vital functions within the society. According to the structural functional theory, each member of the society is shaped by these institutions; therefore, human behaviours are structurally patterned. One of the goals of governments is the alteration of the functions of these institutions according to their vision of the society. Nock (1987) mentions that since structuralism presents the society as a complex organism that should always be kept stable, the dysfunction or change in even one of its social structures will reverberate in other spheres of social life - be it at the macro or micro levels (p. 12). At this juncture, it is pertinent to ask: what are the implications of this theory on the influence of globalisation within the society? The (practical) responses to this question will be examined later in the section on questionnaire data analysis. What follows now is an overview of the partnership between religion and psychological sciences.

\section{Religion and Psychological Sciences: Patterns of Emerging Partnership}

The relationship between the practice of religion and psychological sciences has moved from sheer antagonism to 
constructive integration. Many reasons account for this development, prominent among which is the globalising effect of knowledge and interdisciplinary studies. Clinical psychology has been the major domain for integration because it treats people with various problems traceable to the mind. Yet Gorsuch (2002) cautions that there are some areas of clinical psychology that ought not to be integrated with the practice of religion because the latter involves values and ethics (p. 111). Perhaps, it is because of this or other reasons that some Christians suggest that psychology, viewed as a 'profane' science, has nothing to contribute to the practice of religion or spirituality.

\section{Meaning of Psychology and Christian Spirituality}

Morphologically speaking, the term 'psychology' is a compound word. It is derived from two Greek words: psyche (mind) and logos (knowledge or study). Hence, etymologically, psychological sciences are directed towards a study of the mind. The mind is considered by many to be the seat of human actions and interactions. Based on this postulate, psychology becomes the scientific inquiry into human behaviour within its immediate context. From the literal meaning of psychology, it can be seen that this scientific study deals with human interiority (the mind), precisely as the 'foundation' of human actions. As such, it has much to do with spirituality that richly engages with the noncorporeal aspect of the human person (Ruffing, 2011, p. 308). This definition of psychology excludes the studies of animal behaviour given that spirituality concerns human beings only.

As personality science, psychology provides a lot of resources that aid a better understanding of the human person and his/her integral wellbeing. The discoveries in the field of developmental psychology, experimental psychology, analytical psychology, psychoanalysis, clinical psychology, transpersonal psychology and other related branches of personality science have dug into observable human experiences, thereby offering possible explanations to behaviours that were hitherto considered paranormal or abnormal. In this wise, one is able to make a distinction between spirit possession and psychotic pathologies: groundless or reasonable fear, vision or hallucination, depression or spiritual darkness and psychological or spiritual trauma. 
Transpersonal psychology claims to integrate the spiritual realm and transcendental being with the scientific study of human behaviour. Specialists in this area affirm that human beings relate with the Supreme Being or God and this relationship influences every religious adherent. Against this backdrop, Sutich (1969) submits that transpersonal psychologists hardly describe religious experience in the early Freudian sense as illusion or childhood neurosis. Rather, they see the human experience of the divine as the sacralisation of earthly existence: a medium through which human beings encounter the transcendent (p. 15). With this relational understanding of psychology, the possibility of integrating spirituality with the scientific study of human behaviour as conditioned by the immediate context and other environmental factors becomes clear.

Psychology and the developments in personality types have enhanced the understanding of human behaviours as well as interpretations of their actions. This progress is enhancing selfknowledge which in turn benefits the choice of spirituality that suits one's personality. Personality psychology indicates that every human being is different and this individual difference enables a better understanding of human nature (Meyers, 1993, p. 29). Therefore, the scientific study of human behaviour will be of an immense benefit to spirituality and the society. Notton and Jacobs (2001) agree that many psychotherapists and counsellors make use of the Enneagram personality types in helping their clients solve some of life's enigmas. This is very useful for spiritual development because knowledge of self is crucial to growth in the spirit (p. 100).

With respect to spirituality, it is worth noting that religion is a cultural concept etymologically derived from two Latin words: re and ligare. Re is a prefix which connotes something done again and again, while ligare means to bind oneself to another. Hence, from its Latin root, religion denotes binding oneself again and again to a divine being through prayers, value based praxis, sacrifices and acts of faith. This etymological approach does not, however, exhaust the meaning of religion. For his part, Macionis (2005) writes that religion concerns realities that transcend the boundaries of human knowledge and as a social institution, involves beliefs and practices concerning the concept 
of the sacred (p. 489). Spirituality has to do with personal and relational dimension to value-laden interactions with the sacred that is informed by narratives, myths, revelation and sacred texts. Additionally, spirituality is as 'an individual's inner life, his ideals, attitudes, thoughts, feelings and prayers towards the Divine, and about how he expresses these in his daily way of life' (Schreurs, 2002, p. 25). Consequently, Duke (2014) argues that the functional dimension of religion can be regarded as existential spirituality because it demonstrates how religious beliefs regulate the details of the everyday life of adherents (p. 50).

According to the adherents of the Christian faith, Christian spirituality is centred on the person of Jesus Christ acclaimed as God, the meaning and goal of human existence. As a corollary, Christian spirituality is informed by the human experience of the God of Jesus Christ, Christian scriptures and traditions. Given that the relationship between God and human beings as well as among the latter is observable, a scientific study of Christian spirituality is possible. To this effect, Schneiders (2011) states that:

Christian spirituality as an academic discipline studies the lived experience of Christian faith, the subjective appropriation of faith and living of discipleship in their individual and corporate actualization(s)....[It is] the experience of conscious involvement in the project of lifeintegration through self-transcendence toward the horizon of ultimate value one perceives....This life of faith and discipleship constitutes the existential phenomenon that Christian spirituality as discipline studies. (p. 16)

The experience of Christian faith becomes a life-long process by means of which the faithful integrate the values taught by Jesus Christ through the mystery of His incarnation. Since they believe that the deposit of this experience lies within the ecclesial community, Christian spirituality is not a mere personal journey. It needs the support and discerning guidance of the Church wherein one identifies himself or herself as a member. One can observe varieties of Christian experiences that shape particular denominations' expression of faith in Jesus Christ; this will undoubtedly influence how psychological sciences are integrated. 
From this flows the plurality in Christian spirituality: Roman Catholic, Orthodox, Lutheran, Anglican, Presbyterian, Methodist, Pentecostal, etc. The questionnaire for this study was given to Christians from the Roman Catholic, African Pentecostal and Neo-Pentecostal traditions. African Pentecostals and NeoPentecostals belong to indigenous charismatic-like movements. According to Kalu (2008), 'Each of the indigenous group designates itself by its ministerial emphasis, such as evangelicalism, deliverance, intercession, fellowship... theological emphasis such as prosperity, holiness, witchcraft cleansing, spiritual warfare, prophecy' (p.15).

Members from the Roman Catholic, African Pentecostal and Neo-Pentecostal churches were selected for this study because of the following reasons. Firstly, the research wanted to establish if difference in doctrinal beliefs between mainline churches (like the Roman Catholic Church) and African Independent churches (like the Pentecostal and Neo-Pentecostal churches) significantly influence how both groups respond to the developments in psychological sciences and the culture of globalisation. For this reason, Anglicans, Lutherans, Methodists, and Presbyterians (who fall under the mainline churches) were not given the questionnaire. Secondly, the mainline churches have a firmer institutional control of charismatic initiatives while the Pentecostal and NeoPentecostal churches exercise lesser restraint on how vibrant Pentecostal-like programmes are utilised. Consequently, this work is interested in discovering how these different mind-sets shape the application of psychology-based-aids and the globalisation apparatus to the pastoral environment.

Remarkably, Schneiders (2011) avers that the main focus of Christian spirituality as a field of study is the experience of the spiritual life as human experience (p. 18). This means that a scientific study of Christian spirituality is not confessional; consequently, anybody can be engaged in it. A believer needs to bracket his or her faith and rather concentrate on the experiences of those who attempt to replicate in their lives the teachings of Jesus Christ. These experiences ought to transform the life of those who practice this religion. Since the expected transformation is observable in one's quality of life and the betterment of the society at large, sciences that aim at improving the quality of 
human life are not counter-productive to Christian spirituality. So the question is: what are the contributions of psychology to Christian spirituality?

\section{Contributions of Psychological Sciences to Christian Spirituality}

Firstly, psychology has contributed to a better understanding of human personality. Meyer-Briggs' personality and Enneagram programmes are key psychological tools for describing, improving upon and remedying personality types. Since selfunderstanding is crucial to relating with God and others, personality psychology is important for spiritual growth. Based on this, growth in Christian spirituality will benefit much from a proper understanding of the self through the help of psychological sciences. For example, introverts and extroverts will be encouraged to take on spiritual exercises that suit their personality types with a view to overcoming unnecessary conflicts caused by lack of self-understanding. An introvert who is more drawn to meditative prayers will be encouraged to do more of that rather than being worried about his or her inability with respect to vocal prayers.

Secondly, the field of psychoanalysis has unveiled the relationship between the subconscious and human actions. By probing into the subconscious, psychoanalytic techniques have diagnosed and resolved some human problems. It is possible to manage anxiety-related problems by probing into the human subconscious self. This approach is very helpful when dealing with psychotic issues. By means of this approach, Christian ministers or pastoral agents are able to make a distinction between diabolical/spiritual cases and clinically psycho-somatic illness. When this is done, diabolical cases will be hardly confused with clinical pathologies and vice-versa.

Thirdly, social psychology is of immense help when one considers the management of people in Christian communities. Since human beings are informed and formed by various social factors that influence their perception of themselves and the world, dissemination of the faith on which Christian spirituality is built calls for an average knowledge of social psychology. This will help Christian ministers to be acquainted with the cultural taboos 
of their environment and consequently, dialogue with the community using the values of the gospel. When this is done, unnecessary conflicts between the people and Christian faith will be averted.

Fourthly, developments in guidance and counselling are fruits of extensive research in the field of psychology. These developments are therapeutic to the human person and invariably beneficial to spiritual growth. Marriage counselling sessions that are faith-based have much to benefit from scientific developments in the field of psychology. For example, a technical knowledge of these counselling tools will benefit marriage counsellors as they deal with marital crises. The addition of these techniques to scriptural resources will enrich the help made available to married couples in times of need.

Fifthly, Plante (2011) describes how clinical psychology deals with the assessment, management and treatment of mental pathologies induced by stress or imbalance of organic substances in the body (p. 50). Sometimes, a mental sickness presents itself as a spiritual problem. For example, depression can be misdiagnosed as spiritual darkness. Additionally, psychological trauma apparently looks like spiritual trauma. When, at the crossroads of uncertain diagnosis, knowledge of clinical psychology will prove helpful to clear these doubts in order to help those who are afflicted with one kind of mental illness or the other.

Sixthly, Lartey (2003) proposes an intercultural approach to counselling that places a high premium on cultural sensibilities when one is attending to the pastoral needs of people in traditional African societies. According to him, this method of counselling explores the complex web of relationships and cultural influences within the African society as a condition for the application of Christian convictions to the problems of those who are both African and Christian (pp. 154-158). In addition, Lartey (2013) developed this intercultural approach to counselling in his postcolonial perspectives on pastoral theology. In this work, he uses a diagram to explain that every experience should be analysed in its situation before breaking down the theological context wherein such an occurrence falls. Further, before arriving at any pastoral action, the theology should be critiqued (p. 5). The merit of this approach lies, inter alia, in its accentuation of the particularity of 
every pastoral challenge, psychological or otherwise.

\section{Methodology}

As observed earlier, globalisation has an enormous impact upon social structures of contemporary society. The functional implications of this cultural phenomenon for structural functionalism are evident because they have changed the patterns of governance, religious faith and its communication: family life, interdisciplinary interactions, commerce, pattern of pastoral approach, etc. Since the interest of this research is on how young Christians are adapting to trends in pastoral care that integrates religious practice with psychological sciences in the light of globalisation, the quota sampling technique was used in the distribution of questionnaire.

Quota sampling is one of the research methods for quantitative analysis in the social sciences. It is used when major research variables are of interest to the researcher. De Vaus (2002) explains that the principal aim of this quantitative research method is arriving at a representative sampling, without random selection, given that the quotas of particular types of subjects have already been mapped out beforehand (p. 90). For this work, the age bracket of the young people (between 17 and 29 years) was chosen. The age specification of these young adults is informed by the studies of Sefton-Green (1998, p. 91) and Taft (2007, p. 206). In addition, the characteristics of the sample quotas are young Christians who belong to various Christian denominations. Most of them do not have a highly professional understanding of globalisation and psychological sciences though show reasonable commitment to the praxis of Christian faith. Given the homogeneous nature of such groups and the small sample size of the respondents used for the study, Suen and Ary (1989) suggest that sample statistics will fairly represent the population parameter under investigation (pp. 46-47).

The questionnaire was administered to young Christians in Calabar Municipality, Cross River State in Nigeria. A total of 250 copies of the questionnaire were distributed to the target audience but 172 were returned. 34.6 per cent of the respondents were male while 65.4 per cent represented the female gender. Concerning the financial status of the respondents' families it was noticed that 24 . 